This item was submitted to Loughborough's Research Repository by the author.

Items in Figshare are protected by copyright, with all rights reserved, unless otherwise indicated.

\title{
Passive range of motion of the hips and shoulders and their relationship with ball spin rate in elite finger spin bowlers
}

PLEASE CITE THE PUBLISHED VERSION

https://doi.org/10.1016/j.jsams.2019.04.012

\section{PUBLISHER}

Elsevier ( Sports Medicine Australia

VERSION

AM (Accepted Manuscript)

\section{PUBLISHER STATEMENT}

This paper was accepted for publication in the journal Journal of Science and Medicine in Sport and the definitive published version is available at https://doi.org/10.1016/j.jsams.2019.04.012

LICENCE

CC BY-NC-ND 4.0

\section{REPOSITORY RECORD}

Sanders, Liam, Steve J. McCaig, Paul Felton, and Mark King. 2019. "Passive Range of Motion of the Hips and Shoulders and Their Relationship with Ball Spin Rate in Elite Finger Spin Bowlers”. Loughborough University. https://hdl.handle.net/2134/38184. 


\title{
Passive range of motion of the hips and shoulders and their relationship with ball spin rate in elite finger spin bowlers
}

\author{
${ }^{1}$ L. Sanders, ${ }^{2}$ McCaig, S. ${ }^{1}$ P.J. Felton and ${ }^{1}$ M.A. King. \\ ${ }^{1}$ School of Sport, Exercise and Health Sciences, Loughborough University, Leicestershire, LE11 3TU, UK \\ ${ }^{2}$ English Institute of Sport, Loughborough University, UK
}

\begin{abstract}
Objectives: Investigate rotational passive range of motion of the hips and shoulders for elite finger spin bowlers and their relationship with spin rate.

Design: Correlational.

Methods: Spin rates and twelve rotational range of motion measurements for the hips and shoulders were collected for sixteen elite male finger spin bowlers. Side to side differences in the rotational range of motion measurements were assessed using paired $t-$ tests. Stepwise linear regression and Pearson product moment correlations were used to identify which range of motion measurements were linked to spin rate.

Results: Side to side differences were found with more external rotation $(p=0.039)$ and less internal rotation $(p=0.089)$ in the bowling shoulder, and more internal rotation in the front hip $(p=0.041)$. Total arc of rotation of the front hip was found to be the best predictor of spin rate $(r=0.552, p=0.027)$, explaining $26 \%$ of the observed variance. Internal rotation of the rear hip $(r=0.466, p=0.059)$ and the bowling shoulder $(r=0.476$, $p=0.063)$ were also associated with spin rate.

Conclusions: The technique and performance of elite finger spin bowlers may be limited by the passive range of motion of their hips and shoulders. The observed side to side differences may indicate that due to the repetitive nature of finger spin bowling adaptive changes in the rotational range of motion of the hip and shoulder occur.
\end{abstract}

Keywords: cricket, spin bowling, hip, shoulder, bilateral differences

\section{INTRODUCTION}

Spin rate is considered a major contributor to finger spin bowling success. ${ }^{1}$ The finger spin bowling action is an example of an overhand throw where energy generated in the lower extremities is transferred through the trunk to the upper extremity and finally to the ball. ${ }^{2-3}$ This movement places asymmetrical impacts and loads on the upper and lower extremities. ${ }^{4}$ While studies have examined the impact of these asymmetrical loads on the rotational passive range of motion (PROM) of the hip and shoulder joints in overhand throwing activities such as baseball and tennis, ${ }^{4}$ research on the rotational PROM and its effect on performance in elite finger spin bowlers is scarce.

Hip and pelvic motion has been found to be an essential component of the finger spin bowling action. ${ }^{2-3}$ There are no studies however reporting the rotational PROM in elite finger spin bowlers. Studies investigating hip rotation PROM in baseball have been conducted with conflicting results. Although some studies have reported finding more internal rotation and less external rotation PROM in the stance leg compared to the stride leg, ${ }^{4-6}$ others have found no differences. ${ }^{7-9}$

The movement of the bowling arm is also considered important in finger spin bowling, with the long-axis rotation of the upper-arm previously linked with spin rate. ${ }^{2-}$ 3 Research investigating side to side differences in shoulder rotation PROM is common in baseball, but only Sundaram et al. ${ }^{10}$ has investigated this for finger spin bowlers. They found that in academy spin bowlers the bowling shoulder had more external rotation and less internal rotation PROM than the non-bowling shoulder. A finding which agrees with most research on baseball pitchers. ${ }^{11-14}$ 
Other studies on cricketers have been descriptive or compared shoulder range of motion in cohorts with and without shoulder pain. ${ }^{10,15-17}$ Although one study has compared lumbar and hip PROM in female fast bowlers with and without lower back pain. ${ }^{18} \mathrm{~A}$ similar theme is found when considering overhand throwing or striking skills with descriptive or comparison studies grouping participants based on either: injury, ${ }^{19-20}$ age, ${ }^{21-22}$ gender, ${ }^{7,23}$ sport, $^{7}$ or playing role. ${ }^{8,10}$ The only studies investigating PROM on performance investigated hip PROM and its relationship with pitching kinematics and ball velocity.5,24 Both studies investigated the effect of the total arc of hip rotation PROM of the stance hip on performance in professional baseball pitchers and observed significant correlations with the amount of external rotation torque at the shoulder ${ }^{24}$ and ball release velocity ${ }^{5}$.

Although descriptive hip and shoulder rotational PROM data exists for a range of overhand throws or striking skills, it has yet to be defined in elite finger spin bowling. Furthermore, the relationship between hip and shoulder rotation PROM measurements and performance remains unknown. The aim of this study was to investigate rotational PROM for the hips and shoulders in elite finger spin bowlers and their relationship with spin rate.

\section{METHODS}

Sixteen males (mean \pm SD: age $22.2 \pm 4.0$ years; height $1.81 \pm 0.66 \mathrm{~m}$; body mass $78.9 \pm 12.3 \mathrm{~kg}$ ) identified as "elite finger spin bowlers" by the England and Wales Cricket Board (ECB) spin bowling national coach participated in this study. A bowler was considered elite if they were either a member of the England men's senior, A or U19 cricket team, or a current professional first-class county player identified by the ECB as having the potential to play international cricket within the next 5 years. The testing procedures were explained to each bowler and informed consent was obtained in accordance with the guidelines of the Loughborough University Ethical Advisory Committee.

Prior to bowling, each bowler underwent a series of PROM measurements, as described in Table 1. The order of the measurements was kept consistent with the left-hand side of the body being assessed first. Each PROM measurement was performed by the same examiner, who was an experienced physiotherapist with a Master's degree in manipulative therapy. 
Table 1: Description of PROM measurements

\begin{tabular}{|c|c|c|c|c|}
\hline Assessment & Participant start position & Procedure & Measurement & $\begin{array}{c}\text { Reported } \\
\text { intra-rater reliability }\end{array}$ \\
\hline \multicolumn{5}{|l|}{ shoulder } \\
\hline $\begin{array}{l}\text { internal } \\
\text { rotation }\end{array}$ & $\begin{array}{l}\text { Crook lying, shoulder abducted } \\
\text { to } 90^{\circ} \text { with elbow flexed to } 90^{\circ} \\
\text { and forearm in mid-prone. }\end{array}$ & $\begin{array}{l}\text { Examiner passively internally rotates the } \\
\text { shoulder until end of range whilst stabilising } \\
\text { the scapula and humeral head. }\end{array}$ & $\begin{array}{l}\text { An inclinometer was placed on the posterior } \\
\text { aspect of the forearm just distal to the wrist } \\
\text { joint. The angle between the forearm and the } \\
\text { vertical was recorded. }\end{array}$ & $\operatorname{ICC} 0.73^{25}$ \\
\hline $\begin{array}{l}\text { external } \\
\text { rotation }\end{array}$ & $\begin{array}{l}\text { Crook lying, shoulder abducted } \\
\text { to } 90^{\circ} \text { with elbow flexed to } 90^{\circ} \\
\text { and forearm in mid-prone. }\end{array}$ & $\begin{array}{l}\text { Examiner passively externally rotates the } \\
\text { shoulder until end of range whilst stabilising } \\
\text { the scapula and humeral head. }\end{array}$ & $\begin{array}{l}\text { An inclinometer was placed on the anterior } \\
\text { aspect of the forearm just distal to the wrist } \\
\text { joint. The angle between the forearm and the } \\
\text { vertical was recorded. }\end{array}$ & $\operatorname{ICC} 0.92^{25}$ \\
\hline \multicolumn{5}{|l|}{ hip } \\
\hline $\begin{array}{l}\text { internal } \\
\text { rotation }\end{array}$ & $\begin{array}{l}\text { Sitting on edge of plinth with } \\
\text { both knees flexed to } 90^{\circ} \text {. } \\
\text { Participant lies back into supine } \\
\text { and flexes non-testing leg, so its } \\
\text { foot is resting on the plinth. }\end{array}$ & $\begin{array}{l}\text { Examiner passively internally rotates the hip } \\
\text { until the pelvis is observed to move. }\end{array}$ & $\begin{array}{l}\text { An inclinometer was placed on the superior } \\
\text { part of the medial border of the tibia just } \\
\text { inferior to the medial condyle. The angle } \\
\text { between the tibia and the vertical was } \\
\text { measured. }\end{array}$ & $\operatorname{ICC} 0.78^{25}$ \\
\hline $\begin{array}{l}\text { external } \\
\text { rotation }\end{array}$ & $\begin{array}{l}\text { Sitting on edge of plinth with } \\
\text { both knees flexed to } 90^{\circ} \text {. } \\
\text { Participant lies back into supine } \\
\text { and flexes non-testing leg, so its } \\
\text { foot is resting on the plinth. }\end{array}$ & $\begin{array}{l}\text { Examiner passively externally rotates the hip } \\
\text { until the pelvis is observed to move. }\end{array}$ & $\begin{array}{l}\text { An inclinometer was placed on the superior } \\
\text { part of the medial border of the tibia just } \\
\text { inferior to the medial condyle. The angle } \\
\text { between the tibia and the vertical was } \\
\text { measured. }\end{array}$ & ICC $0.80-0.82^{26}$ \\
\hline
\end{tabular}

Once the PROM measurements were completed, a thorough self-selected warm up was conducted prior to bowling. Ten maximal spin deliveries of a good line and length were bowled on a standard length indoor artificial cricket pitch within a purpose-built cricket facility. The spin rate of each delivery was recorded using a Doppler radar system, Trackman (Trackman A/S, Denmark). Trackman measures spin rate in revolutions per minute (RPM), with research showing a typical error of less than 18 RPM compared to motion capture. ${ }^{26}$ The maximum spin rate achieved during these ten trials was used in the statistical analysis.

All statistical analyses were performed within SPSS v.23 (SPSS Corporation, USA). The normality of the variables was confirmed via a Shapiro-Wilk test. Paired student t-tests were used to investigate the side to side differences in the hip and shoulder PROM measurements. An alpha value of 0.05 was used to determine significance and Cohen's d was calculated to determine the effect size of the difference. Correlations between each PROM (independent) variable and spin rate (dependent variables) were assessed using Pearson product moment correlation analyses with an alpha value of 0.05 to determine significance. Due to the exploratory nature of the study, results with alpha values up to 0.1 were noted in the Results and Discussion.

To identify the kinematic parameters which best explain the variation in spin rate, the parameters which were significantly correlated to spin rate were entered as "candidate" variables in a forwards stepwise linear regression model. The entry requirement for the inclusion of a parameter into the regression equation was $p<$ 0.05 with a removal coefficient of $P>0.10$. Similarly, the regression model was 
rejected if the coefficient $95 \%$ confidence intervals included zero, the residuals of the predictor were heteroscedastic or if the bivariate correlations, tolerance statistics or variance inflation factors showed any evidence of multicollinearity. ${ }^{27}$ The normality of the standardised residuals in the regression model was also confirmed via a ShapiroWilk test. The percentage of variance in the dependent variable (spin rate) explained by the PROM (independent) variables in the regression equation was determined by Wherry's adjusted $\mathrm{R}^{2}$-value. ${ }^{28}$ This represents an attempt to estimate the proportion of variance that would be explained by the model had it been derived from the population (elite finger spin bowlers) from which the sample was taken. To overcome the potential limitations of stepwise regressions relying on a single best model, the explained variance for all possible regression equations with the same number of predictor variables as the stepwise solution was determined for comparison.

\section{RESULTS}

The spin rates produced by the 16 participants were in the range of $1484-1929$ RPM (1699 \pm 123 RPM). A significant side to side difference was found with more external rotation PROM in the bowling shoulder (Table 2). Further side to side differences were found when using an alpha of less than 0.1 with less internal rotation PROM in the bowling shoulder and more internal rotation PROM in the front hip.

The only PROM measure found to be linearly correlated to spin rate was the total arc of rotation of the front hip (Table 3). Internal rotation PROM of the rear hip and internal rotation PROM of the bowling shoulder were correlated to spin rate with an alpha value of less than 0.1. These three parameters were put forward as "candidate" variables for entry into the linear regression equation.

Table 2. Range, mean, standard deviation and paired t-test analysis for the dominant and nondominant PROM measurements

\begin{tabular}{|c|c|c|c|c|c|}
\hline \multirow{2}{*}{$\begin{array}{l}\text { Passive range of } \\
\text { motion measure }\end{array}$} & \multicolumn{2}{|c|}{ dominant } & \multicolumn{2}{|c|}{ non-dominant } & \multirow[b]{2}{*}{$p$} \\
\hline & range & mean \pm S.D. & range & mean \pm S.D. & \\
\hline shoulder & \multicolumn{2}{|c|}{ bowling arm } & \multicolumn{2}{|c|}{ non-bowling arm } & \\
\hline internal rotation ( $\left.{ }^{\circ}\right)$ & $62-105.3$ & $77.4 \pm 11.7$ & $65-101.2$ & $83.1 \pm 11.3$ & $0.089^{\star b}$ \\
\hline external rotation $\left({ }^{\circ}\right)$ & $114-163$ & $137.4 \pm 15.7$ & $97-154.8$ & $128.7 \pm 13.5$ & $0.039^{\star * a}$ \\
\hline total arc of rotation $\left({ }^{\circ}\right)$ & $184-231.5$ & $214.8 \pm 13.6$ & $192-244.1$ & $211.8 \pm 14.2$ & 0.282 \\
\hline hip & \multicolumn{2}{|c|}{ rearleg } & \multicolumn{2}{|c|}{ front leg } & \\
\hline internal rotation $\left({ }^{\circ}\right)$ & $21-50$ & $34.3 \pm 8.0$ & $19-54$ & $37.6 \pm 8.8$ & $0.041^{* \star b}$ \\
\hline external rotation $\left({ }^{\circ}\right)$ & $34-68$ & $48.3 \pm 8.4$ & $34-65$ & $45.1 \pm 8.0$ & 0.185 \\
\hline total arc of rotation $\left({ }^{\circ}\right)$ & $61-107.4$ & $82.6 \pm 13.3$ & $67-107$ & $82.8 \pm 10.8$ & 0.957 \\
\hline
\end{tabular}

** Significant difference at the $\mathbf{0 . 0 5}$ level, * Significant difference at the 0.1 level.

${ }^{a}$ medium effect size $\geq 0.50$, ${ }^{b}$ small effect size $\geq 0.30$ (Cohen's d) 
Table 3. Correlations between spin rate and the 12 PROM measurements

\begin{tabular}{|c|c|c|c|c|}
\hline \multirow[b]{2}{*}{ PROM measure } & \multirow[b]{2}{*}{$r$} & \multicolumn{2}{|c|}{ confidence intervals } & \multirow[b]{2}{*}{$p$} \\
\hline & & lower bound & upper bound & \\
\hline \multicolumn{5}{|l|}{ shoulder } \\
\hline internal rotation - bowling arm ( 9 ) & 0.476 & 0.056 & 0.747 & $0.063^{*}$ \\
\hline internal rotation - non-bowling arm $\left({ }^{\circ}\right)$ & -0.139 & -0.553 & 0.403 & 0.607 \\
\hline external rotation - bowling $\left(^{\circ}\right)$ & -0.309 & -0.854 & 0.385 & 0.245 \\
\hline external rotation - non-bowling arm $\left({ }^{\circ}\right)$ & 0.070 & -0.553 & 0.556 & 0.797 \\
\hline total arc of rotation - bowling $\left(^{\circ}\right)$ & 0.052 & -0.673 & 0.676 & 0.848 \\
\hline total arc of rotation - non-bowling arm $\left({ }^{\circ}\right)$ & -0.045 & -0.537 & 0.416 & 0.868 \\
\hline \multicolumn{5}{|l|}{ hip } \\
\hline internal rotation - rear hip $\left({ }^{\circ}\right)$ & $0.485^{\star}$ & -0.092 & 0.776 & $0.057^{*}$ \\
\hline internal rotation - front hip $\left(^{\circ}\right)$ & 0.400 & -0.151 & 0.872 & 0.125 \\
\hline external rotation - rear hip $\left(^{\circ}\right)$ & 0.162 & -0.276 & 0.594 & 0.549 \\
\hline external rotation - front hip $\left(^{\circ}\right)$ & 0.305 & -0.186 & 0.709 & 0.250 \\
\hline total arc of rotation -rear hip $\left(^{\circ}\right)$ & 0.395 & -0.213 & 0.765 & 0.130 \\
\hline total arc of rotation - front hip $\left(^{\circ}\right)$ & $0.552^{* *}$ & 0.204 & 0.817 & $0.027^{* *}$ \\
\hline
\end{tabular}

${ }^{* *}$ Correlation to spin rate significant at the $\mathbf{0 . 0 5}$ level, ${ }^{*}$ Correlation to spin rate significant at the 0.1 level.

The "candidate" variables were investigated initially for multicollinearity using bivariate correlations. Since internal rotation PROM of the rear hip was significantly correlated with total arc of rotation PROM of the front hip with a Pearson's correlation coefficient greater than 0.79 it was removed as a candidate variable. ${ }^{27}$ The best predictor of spin rate was the total arc of rotation PROM of the front hip, which explained $25.5 \%$ of the variation in spin rate. The bowlers with greater total arc of rotation PROM of the front hip characterised the bowlers with the highest spin rates. No other combinations of variables (including those discarded as "candidate" variables) were found when trying all other possible combinations.

\section{DISCUSSION}

The current study aimed to investigate hip and shoulder rotation PROM in elite finger spin bowlers and their relationship to spin rate. The spin rates observed in this study (1699 \pm 123 RPM) were similar to those recorded by Chin et al. ${ }^{1}(1602 \pm 276$ RPM) and Beach et al. ${ }^{3}$ (1584 \pm 264 RPM). Side to side differences were observed in both hip and shoulder rotation PROM measures with the results consistent with previously published data on finger spin bowlers and baseball pitchers. ${ }^{10-14}$ Spin rate was associated with increased rotational PROM of the hips and the shoulders. These results suggest adaptations of the hip and shoulder PROM occur in finger spin bowlers similar to other overhand throwing activities and that their technique and performance may be limited by the PROM of their hips and shoulders.

Although the motion of the hips and pelvis have previously been found to be an essential component of the finger spin bowling action, ${ }^{2-3}$ there are no studies reporting the rotational PROM of the hip in elite finger spin bowlers. The PROM of the hips reported in this study (Table 2) are the first to be reported in elite finger spin bowlers and are similar to ranges previously reported in baseball pitchers. ${ }^{4-9}$ More internal rotation PROM in the front hip was found in this study. This result is similar to previous findings in baseball pitching, where increases in internal rotation PROM of the stance hip have been reported..$^{4-6}$ In baseball pitching, it has been suggested that the side to side differences are adaptive and caused by the high repetition of the action rather than pathologic, with older pitchers reported to have greater PROM. ${ }^{4}$ Future research is required to determine whether similar hip and pelvic loads are 
experienced in finger spin bowling compared to baseball pitching and whether the side to side difference in hip rotation PROM is adaptive or pathologic.

More external rotation PROM $(p<0.05)$ and less internal rotation PROM $(p<$ 0.1 ) of the bowling shoulder was observed when compared to the non-bowling shoulder in this study (Table 2). This is in agreement with the only other study investigating PROM of the shoulder in finger spin bowlers, ${ }^{10}$ and most studies on baseball pitchers. ${ }^{11-14}$ In addition, the total arc of rotation PROM was similar across both shoulders. A shift in symmetrical PROM has previously been suggested to be a protective adaptation that alleviates stress on the glenohumeral joint and increases performance, whereas asymmetric total arc of rotation PROM of the shoulders has been associated with shoulder and elbow injuries in baseball. ${ }^{8}$ These results suggest a similar protective adaptation may occur in elite finger spin bowling as other overhand throwing activities.

The total arc of rotation PROM in the front hip was shown to be the most important PROM measurement with respect to spin rate. This result indicates a relationship may exist between the total arc of rotation PROM of the front leg and the kinematics of the pelvis during the finger spin bowling action. Previous research has found positive correlations with spin rate for both: the front foot orientation at front foot contact and the amount of internal rotation of the front hip. ${ }^{2}$ It is possible that a larger total arc of rotation PROM of the front leg may be linked to either (or both); the amount of internal hip rotation during the finger spin bowling or front foot orientation at front foot contact. A smaller total arc of rotation PROM of the front hip may not only decrease the range of internal rotation possible during the finger spin bowling action but may also prevent optimal front foot contact kinematics being attained.

Although no further correlations were significant with an alpha value less than 0.05 , internal rotation PROM of the rear hip was positively correlated to spin rate with an alpha value less than 0.1 (Table 3 ). The movement of the back leg in the finger spin bowling action between front foot contact and ball release has previously been suggested to aid the rotation of the pelvis about the front leg. ${ }^{2-3}$ It has been proposed in baseball that pitchers require sufficient internal hip rotation PROM of the trail leg to achieve the optimal orientation of the pelvis at lead foot contact. ${ }^{6,9}$ This result indicates that finger spin bowlers may also require sufficient internal hip PROM of the rear leg to achieve optimal orientation of the pelvis at lead leg contact.

Insufficient hip rotation PROM which prevents optimal pelvis kinematics being achieved is likely to cause limitations in the transfer of energy created in the lower extremities to the upper extremities, as well as coordinating the release of the ball towards the target. It is possible that this leads to a break in the kinetic chain within the finger spin bowling action which causes additional stresses in the torso and the upper extremity which may lead to injury, illegal bowling actions or reduced spin rates. For example, Laudner et al. ${ }^{20}$ demonstrated that altered hip rotation PROM had a direct impact on external rotation torque and horizontal abduction of the shoulder during a throwing motion. Further investigation is required to understand how the kinematics and kinetics of the finger spin bowling action are affected by limitations in hip rotation PROM.

The role of the upper arm in finger spin bowling has previously been linked to performance with Beach et al. $^{3}$ reporting that maximum internal shoulder velocity was correlated with spin rate in club level bowlers. Although no statistically significant correlations were observed between any of the shoulder PROM measurements and spin rate, internal rotation PROM of the bowling shoulder was positively correlated to spin rate with an alpha value less than 0.1 (Table 3 ). Research investigating the 
effect of shoulder rotation PROM on performance in overhand throwing is limited, with external rotation rather than internal rotation PROM often the focus. ${ }^{30}$ While the current study observed no relationship between external rotation PROM of the bowling shoulder, the relationship between spin rate and internal rotation PROM of the bowling shoulder appears to conflict with the adaptive changes observed in elite finger spin bowlers (more external rotation PROM and less internal rotation PROM in the bowling shoulder). ${ }^{10}$ It is possible that the adaptive changes at the shoulder do not occur due to the repetitive nature of finger spin bowling but due to the large amount of throwing also required in cricket when fielding. Although this is unknown, it should be an area of future study, if true, throwing workload in finger spin bowlers may need to be monitored to prevent adaptations which could be detrimental to performance occurring.

A limitation of using an elite finger spin bowling population is the restriction it places on the potential sample size. Although a sample of 16 elite finger spin bowlers is a relatively large sample of this population, it only led to one PROM measure being entered in the regression equation. It was therefore decided to comment on measurements from the correlations with an alpha value of 0.1 to identify relationships of potential interest. A further limitation of a small sample size is that it can reduce the power of a study and make small effects harder to notice. In the future, this sample could be added to increase the power and provide further insight into elite finger spin bowling. Another potential limitation is that PROM measures are intra-variable on a number of factors such as the time of day, previous activity and level of warm up. It was decided to allow the bowlers to follow their own self-selected warm ups as they would do in a match environment and control for this by testing PROM pre-warm up. The disadvantage of this method is that some players may achieve a greater increase in PROM after warming up than others. Finally, the PROM measurements obtained in this study were limited to rotations of the hips and shoulders. In the future, the PROM of the other joints in the kinetic chain should be investigated to determine how they also may limit performance of the spin bowling action.

\section{CONCLUSION}

Side to side differences were observed in the rotation PROM of the hips and shoulders in elite finger spin bowlers. The elite finger spin bowlers in this study had more internal rotation PROM of the front hip compared to the rear hip, which may be an adaptive change due to the large number of repetitions involved. Notable side to side differences were also seen at the shoulder with more external rotation PROM and less internal rotation PROM in the bowling arm. Although no difference was observed in the total arc of rotation of the shoulders, this suggests that a protective shift in the PROM may have occurred similar to other overhand throwing activities.

In addition, this study also found that spin rate was linked to a higher internal PROM of the rear hip and total arc of rotation PROM of the front hip. This may indicate that the hips require a sufficiently high rotation PROM to achieve the optimal orientation of the pelvis at front foot contact. Spin rate was also associated with higher internal rotation PROM of the bowling shoulder. A result which may conflict with the protective adaptation found at the shoulder, this may suggest that this adaptation does not occur due to the repetitive nature of finger spin bowling but potentially due to the amount of throwing also required in cricket. Future studies should aim to evaluate the relationships between PROM measurements and finger spin bowling kinematics and kinetics to determine how they limit performance. 


\section{PRACTICAL IMPLICATIONS}

- normative PROM data may help differentiate normal from abnormal motion and educate performance and injury interventions.

- similar side to side PROM differences to other overhand throwing activities allow similar screening and injury protocols to be employed.

- conflict between shoulder PROM adaptation and performance requirement may require throwing workload to be monitored in finger spin bowlers to prevent detrimental adaptations.

- understanding of how PROM measures link to performance can educate talent identification, coach education and injury rehabilitation.

\section{ACKNOWLEDGEMENTS}

The authors would like to acknowledge that was project was part-funded by the England and Wales Cricket Board. There were no additional sources of funding.

\section{REFERENCES}

1. Chin A, Elliott B, Alderson $J$ et al. The off-break and "doosra": Kinematic variations of elite and sub-elite bowlers in creating ball spin in cricket bowling. Sports Biomech 2009; 8(3):187-198.

2. Sanders L, Felton PJ, King MA. Kinematic parameters contributing to the production of spin in elite finger spin bowling. J Sports Sci 2018: 10:1-7.

3. Beach AJ, Ferdinands RE, Sinclair PJ. The relationship between segmental kinematics and ball spin in Type-2 cricket spin bowling. J Sports Sci 2018; 36(10):1127-1134.

4. McCulloch PC, Patel JK, Ramkumar PN et al. Asymmetric hip rotation in professional baseball pitchers. Orthop J Sports Med 2014; 2(2):1-6.

5. Robb AJ, Fleisig $\mathrm{G}$, Wilk $\mathrm{K}$ et al. Passive ranges of motion of the hips and their relationship with pitching biomechanics and ball velocity in professional baseball pitchers. Am J Sports Med 2010; 38(12):2487-2493.

6. Tippett SR. Lower extremity strength and active range of motion in college baseball pitchers: a comparison between stance leg and kick leg. J Orthop Sports Phys Ther 1986; 8(1):10-14.

7. Ellenbecker TS, Ellenbecker GA, Roetert EP et al. Descriptive profile of hip rotation range of motion in elite tennis players and professional baseball pitchers. Am J Sports Med 2007; 35(8):1371-1376.

8. Sauers EL, Huxel Bliven KC, Johnson MP et al. Hip and glenohumeral rotational range of motion in healthy professional baseball pitchers and position players. Am J Sports Med 2014; 42(2):430-436.

9. Laudner KG, Moore SD, Sipes RC et al. Functional hip characteristics of baseball pitchers and position players. Am J Sports Med 2010; 38(2):383-387.

10. Sundaram B, Bhargava SK, Karuppannan S. Glenohumeral rotational range of motion differences between fast bowlers and spin bowlers in elite cricketers. Int J Sports Phys Ther 2012; 7(6):576-585. 
11. Crockett HC, Gross LB, Wilk KE, et al. Osseous adaptation and range of motion at the glenohumeral joint in professional baseball pitchers. Am J Sports Med 2002; 30(1):20-26.

12. Downar JM, Sauers EL. Clinical measures of shoulder mobility in the professional baseball player. J Athl Train 2005; 40(1):23-29.

13. Borsa PA, Laudner KG, Sauers EL. Mobility and stability adaptations in the shoulder of the overhead athlete. Sports Med 2008; 38(1):17-36.

14. Wilk KE, Macrina LC, Fleisig GS et al. Correlation of glenohumeral internal rotation deficit and total rotational motion to shoulder injuries in professional baseball pitchers. Am J Sports Med 2011; 39(2):329-335.

15. Giles K, Musa I. A survey of glenohumeral joint rotational range and non-specific shoulder pain in elite cricketers. Phys Ther Sport 2008; 9(3):109-116.

16. Stuelcken MC, Ginn KA, Sinclair PJ. Shoulder strength and range of motion in elite female cricket fast bowlers with and without a history of shoulder pain. J Sci Med Sport 2008; 11(6): 575-580.

17. Green RA, Taylor NF, Watson L et al. Altered scapula position in elite young cricketers with shoulder problems. J Sci Med Sport 2013; 16(1):22-27.

18. Stuelcken MC, Ginn KA, Sinclair PJ. Musculoskeletal profile of the lumbar spine and hip regions in cricket fast bowlers. Phys Ther Sport 2008; 9(2):82-88.

19. Young SW, Dakic J, Stroia K et al. Hip range of motion and association with injury in female professional tennis players. Am J Sports Med 2014; 42(11):26542658.

20. Li X, Ma R, Zhou H et al. Evaluation of hip internal and external rotation range of motion as an injury risk factor for hip, abdominal and groin injuries in professional baseball players. Orthop Rev 2015; 7(4):6142.

21. Beckett $M$, Hannon $M$, Ropiak $C$ et al. Clinical assessment of scapula and hip joint function in preadolescent and adolescent baseball players. Am J Sports Med 2014; 42(10):2502-2509.

22. Picha KJ, Harding JL, Bliven KC. Glenohumeral and hip range-of-motion and strength measures in youth baseball athletes. J Athl Train 2016; 51(6):466-473.

23. Moreno-Pérez V, Ayala F, Fernandez-Fernandez $\mathrm{J}$ et al. Descriptive profile of hip range of motion in elite tennis players. Phys Ther Sport 2016; 19:43-48.

24. Laudner K, Wong R, Onuki T et al. The relationship between clinically measured hip rotational motion and shoulder biomechanics during the pitching motion. J Sci Med Sport 2015; 18(5):581-584.

25. Dacombe $P$, Ranson $C$, McCaig $S$ et al. A reliability assessment examining the inter- and intraobserver reliability of the current England and Wales Cricket Board musculoskeletal profiling protocol. Br J Sports Med 2011; 45:e1.

26. Malliaras $P$, Hogan $A$, Nawrocki $A$ et al. Hip flexibility and strength measures: reliability and association with athletic groin pain. Br J Sports Med 2009; 43:739744.

27. Chapman SJ. Spin it to win it: A comparison of constraints-led versus traditional coaching approaches. Doctoral dissertation, Queensland University of Technology, 2015.

28. Field AP. Discovering statistics using IBM SPSS statistics, 4th ed., London, Sage, 2013. 
29. Wherry R. A new formula for predicting shrinkage of the coefficient of multiple correlation. The Annals of Mathematical Statistics 1931; 2:440-457.

30. van den Tillar R. Comparison of range of motion tests with throwing kinematics in elite team handball players. J Sports Sci 2016; 34(20):1976-1982. 